\title{
THE MULTI-FACETED IMPLEMENTATION OF TELEPRACTICE TO SERVICE INDIVIDUALS WITH AUTISM
}

\author{
MiChelle BOISVERT, PH.D., CCC-SlP, NerissA HALl, M.A., CCC-SLP, \\ MARY ANDRIANOPOUlOS, PH.D., CCC-SLP, JEANNE CHACLAS, MBA \\ UNIVERSITY OF MASSACHUSETTS, AMHERST
}

\section{ABSTRACT}

Telepractice is a method of service delivery in which professionals provide intervention, assessment and consultation services to individuals through the use of telecommunication technologies. In response to the nationwide school-based shortage of speech-language pathologists, telepractice has emerged as a viable way to reach underserved clients. Telepractice has the potential to extend to populations in need of services, including those diagnosed with autism. This paper examines an evidence-based clinical model for the delivery of telepractice services and describes the policies and procedures required for assessing individual need, confidentiality, technology, training and documentation within a telepractice program. Two clinical case studies involving individuals diagnosed with autism are described and provide initial evidence for the use of telepractice as a practical method for direct and consultative service delivery. Results indicated that both the student receiving direct services, and the treating clinician receiving consultative services via telepractice, demonstrated an increased skill level in target domains.

Key Words: Speech-language pathology, autism, telepractice, clinical model, direct service, supervision, AAC

\section{INTRODUCTION}

Telepractice is rapidly gaining nationwide interest for the provision of intervention, diagnostic and consultation services in response to the chronic shortage of schoolbased speech-language pathologists (SLPS) in the United States (American Association for Employment in Education, 2008; U.S. Department of Education, 2012). The shortage of SLP personnel creates the opportunity for researchers and clinicians alike to determine if telepractice can become a practical, cost-effective and valid form of delivery for services. Access to high-speed Internet and video conferencing systems facilitates this method by enabling public schools, clinics and hospitals, and other end-users to connect to professionals and specialists regardless of their geographical location.

Traditional models of service delivery have involved, and in some cases required on-site, face-to-face interactions between the clients (American Speech Hearing Association, 2005, 2010), students in training and/ or SLP specialists, and include tangible written or visual materials and stimuli. The advancement of technologies and high speed Internet enable SLPs to simulate therapeutic sessions in virtual environments. SLPs utilize the power and flexibility of the Internet to conduct screenings and diagnostic evaluations; and provide intervention, consultation, and follow-up services utilizing telepractice methodologies.

Telepractice has the potential to revolutionize how SLP services are delivered, particularly with respect to individuals with autism. The number of individuals in the U.S. diagnosed with autism continues to grow annually. Recent estimates suggest that autism affects approximately 1 in every 88 children (Centers for Disease Control and Prevention, 2012) and as many as $61 \%$ of children with autism initially present with little to no functional speech (Koegel, Matos-Fredeen, Lang, \& Koegel, 2011; Schlosser \& Wendt, 2008; National Research Council, 2001). It is estimated that approximately $40 \%$ of children with ASD remain nonverbal (National Autism Center, 2011) with a significant proportion of this population requiring alternative communication modes for expressive communication (Mirenda \& lacono, 2009). Many of these children reside in areas where public resources are scarce and have limited access to qualified SLP professionals. Gaining access to services via telepractice allows for the potential to improve long-term outcomes for this population as it enables the implementation of evidence-based interventions. The National Professional Development Center on Autism 
Spectrum Disorders (n.d.) has identified approximately 24 evidence-based interventions for individuals with autism. Interventions such as functional communication training and behavioural assessment, computer aided instruction, parent implemented intervention, video modeling, peermediated intervention, the use of speech generating devices, pivotal response training and social narratives may be appropriate for a telepractice delivery method based upon the intended communication skill targeted with these approaches.

Telepractice is emerging as a viable method not only for delivery of SLP services to clients in remote regions, but also for related services (Boisvert, et al., 2010). To date, several published studies support the use of telepractice applications for the delivery of health care services. The results of these studies show that telepractice has significant benefits for the provision of health-related services (Miller, Morgan \& Wood, 2009). The purpose of this paper is to introduce a telepractice service delivery continuum as it relates to direct and indirect SLP services. In addition, this paper presents two case studies that provide evidence regarding the potential and efficacy of telepractice as a remote service delivery model.

\section{Clinical MODEL FOR A TELEPRACTICE SERVICE DELIVERY PROGRAM}

To date, a small number of published studies supports the use of telepractice for the provision of both direct and indirect speech and language services. Direct telepractice services, also known as synchronous services, can be used to provide real-time services to individuals in need of treatment. These services are consistent with traditional in-person sessions; however, the mode of delivery incorporates the use of videoconferencing and screen-sharing software. By using these technologies, the off-site SLP is able to communicate and interact with the client and present stimuli and activities that target specific intervention goals and objectives. Moreover, the procedures followed utilizing telepractice service delivery methodologies must ensure that the quality of services received through telepractice are equivalent to that of traditional on-site services.

Telepractice facilitates Active Consultation practices, an indirect service delivery strategy. Active Consultation implements a combination of Bluetooth ${ }^{\mathrm{TM}}$ technology and videoconferencing software to inconspicuously provide real-time feedback to an on-site professional. Active Consultation services are employed to facilitate guided training to individuals at an on-site location while they are working with the client. The off-site supervising professional or clinician is able to observe all interactions through videoconferencing software and provide scaffolded instruction. Through Active Consultation, offsite professionals provide directions, recommendations and strategies that target specific skills within the context of services.

The strategic use of these technologies and telepractice methodologies enable a continuum of direct and indirect services regardless of locale and issues related to personnel shortages. In the sections that follow, guidance for providing services through telepractice and Active Consultation is provided, including an outline to help troubleshoot various decision-making processes, technical logistics and clinical strategies needed to support an evidence-based telepractice service delivery program.

\section{IDENTIFYING THE NEED}

Prior to implementing any technologies to provide SLP clinical services, a thorough needs assessment is essential for the successful implementation of a telepractice program. The on- and off-site telepractice team need to develop a plan that addresses the following components detailed by the American Speech Language and Hearing Association (2010): a) current student/ school need; b) current resources and infrastructure; c) required technology/equipment; d) tools used for student assessment and treatment; e) strategies for documentation and reporting; f) schedule for professional and caregiver education; g) schedule for student/client services; and h) general communication strategies. The needs assessment identifies the specific goals, practices and problems that the technology will support and clearly describes the benefits and limitations of the technology, including various strategies to integrate new technologies. Establishing an ongoing program evaluation of the quality of services and clinical outcomes helps validate the use of telepractice and thus, improves the overall program.

\section{STUDENT DATA, PRIVACY AND CONFIDENTIALITY PROTOCOLS}

It is of the utmost importance for telepractice programs to be implemented and administered to adhere to procedures that ensure confidentiality, student privacy and data security. The Family Educational Rights and Privacy Act (FERPA) and the Health Insurance Portability and Accountability Act (HIPAA) are federal mandates that ensure the protection of student, client data, privacy, and confidentiality.

FERPA applies to elementary, secondary, and adult students in public and private institutions that receive federal funds (Family Educational Rights and Privacy Act, 1974). This mandate provides explicit regulations regarding the privacy and release of students' educational records (Van Dusen, 2004; Toglia, 2007). Educational institutions subject to FERPA are prohibited from disclosing the educational records of students or 
personally identifiable information, without a guardian's or eligible student's written consent. When initiating a telepractice program, obtaining the caregiver's informed consent fosters student safety and privacy. Ethical guidelines require professionals and clinicians to fully inform all parties of the nature and possible effects of the services rendered (Denton \& Gladstone, 2005; American Speech-Language-Hearing Association, 2010). The process of obtaining consent includes providing a detailed description of the technology to be used and services to be delivered. A description must be furnished to all relevant parties regarding the differences between telepractice services compared to traditional on-site services. Moreover, the positive and negative consequences must be outlined with respect to the potential outcomes and necessary steps and procedures that might result with telepractice services (Denton \& Gladstone, 2005).

HIPAA addresses the security and privacy of protected health information (Health Insurance Portability and Accountability Act, 1996). There are several methods to meet HIPAA requirements when providing telepractice, such as the use of data encryption, security certificates and virtual private networks (American SpeechLanguage-Hearing Association, 2010). All computers and laptops used for telepractice should have a secure firewall and up-to-date anti-virus software. These security measures help to reduce the likelihood that a virus will attack the computer and facilitate the protection and privacy of student/client/patient information. All SLP professionals must be trained in security protocols that include password management and computer monitor placement. All electronic data that passes between participants must have a 256-bit Secure Socket Layer encryption.

\section{TECHNICAL REQUIREMENTS AND QUALITY STANDARDS}

Technological competence is pivotal in the successful delivery of telepractice. An established standardized protocol maximizes the reliability and effectiveness of remote service delivery. There are essential items that must be available at both the provider's and client's locations. These items include a computer/laptop with a large monitor, high-speed Internet access, webcam, a video conferencing system, and a screensharing program. A number of additional factors must be considered when administering intervention services via telepractice. These include technical requirements (such as bandwidth connection), Internet usage policies, especially when multiple users occupy the Internet concurrently, collaboration with on-site information technology (IT) technicians or technical support/administrators, and the need for supplementary equipment.

\section{SUPPLEMENTARY EQUIPMENT AND RESOURCES}

Supplementary equipment can enhance the overall quality of direct/indirect services provided via telepractice. Additional tools, devices and equipment vary according to the application of services and the desired outcomes. For example, additional monitors, web and document cameras, headphones, cell phones, Bluetooth ${ }^{\mathrm{TM}}$ earpieces, and back-up storage devices may be needed for telepractice services. For direct services, a large monitor (over 20 inches) or dual monitors support the dynamic exchanges that occur when providing telepractice for clinical services. The visual infrastructure of the equipment must support the clinician's ability to provide visual cues and models, as well as use non-verbal body language (such as gestures and facial expressions) via video conferencing. External webcams (versus a built-in webcam) often provide a wider visual field of the remote environment and provide freedom of movement as the camera can be repositioned in any direction. The use of motorized pan and tilt webcams enable the off-site SLP to remotely control the movement and zoom of the camera to obtain different vantage points of the on-site environment. External speakers for sound, headsets, and microphones enhance the audio quality transmitted and received between the participants.

The Internet provides a significant amount of webbased materials and activities that lend themselves to telepractice. When a SLP is determining what digital information to present through screen-sharing software, the visual layout of the screen must be taken into account. "Visual clutter" refers to external visual stimuli, such as advertisements, chat boxes, and tool/navigation bars on a webpage that might distract the client from the content or intended purpose of the activity. To address this issue, the clinician must be able to remove or hide the visual distraction on the page. Presenting material in full screen or using the screen's zoom feature allows clinicians to enlarge the material or activity, thereby eliminating unwanted items from view.

\section{COLLABORATING WITH ON-SITE PERSONNEL AND LIAISONS}

On-site personnel and liaisons are an essential component of a successful telepractice program. Support personnel can include caregivers/parents, general and special educators and assistants, paraprofessionals, e-helpers, and speech language pathology assistants (SLP-As). The support personnel's role must be clearly identified. There must not be any misrepresentation of the credentials of the on-site support personnel. It is essential to distinguish between an on-site helper and a SLP-A. If the support personnel assumes an active role and is involved in the provision of services (i.e., provides 
and plans additional on-site interventions), then the support personnel's role may be considered a SLP-A. If the person providing therapy is, indeed acting as a SLP-A, the required credentials and requirements must be obtained to legally practice in the state where services are rendered. Likewise, the SLP providing services must adhere to the supervisory guidelines mandated by the state in which the services are being provided.

\section{MONITORING STUDENT PROGRESS AND QUALITY ASSURANCE}

Regardless of the equipment, tools and/or services being implemented, assessment and intervention services provided through telepractice should be evaluated for clinical effectiveness and must include client, caregiver, and provider satisfaction surveys to obtain quality assurance outcome measures (American Speech-Language-Hearing Association, 2010). Ongoing documentation and progress monitoring should occur using a safe, secure caseload management program. For the purpose of telepractice, web-based systems are ideal as they support universal access and the collaboration of all team members regardless of geographical location. The documentation for telepractice is comparable to traditional on-site services in that the following information should be included: 1) date of the session; 2) length of service; 3) technical issues encountered; 4) intervention goals addressed; and 5) data collected for each target objective. Clinicians must document student progress and outcomes toward each goal addressed, as well as any additional referrals and/or recommendations.

The assessment of service quality is an ongoing process. Well established communication processes among the relevant parties and participants directly enhance the overall quality of the intervention and/or consultation services provided via telepractice and Active Consultation. Both on-site and off-site staff must have an organized and effective method implemented through which concerns, questions and information can be shared among all relevant parties and participants.

\section{IT SUPPORT}

Consultation of on-site Information Technology (IT) support is required when initiating a telepractice program, given the IT professional's knowledge of the technical infrastructure and usage at an on-site location. The collaboration between the off-site SLP and on-site IT personnel will ease the technology selection process and help with troubleshooting when issues arise (Juenger, 2009). The on-site IT personnel should be made aware of the times and dates that telepractice services are being provided and may require IT support. The on-site IT personnel facilitate ongoing quality assessments, manage firewalls and ensure sufficient bandwidth to prevent interruption or degradation of the Internet connection (American Speech-Language-Hearing Association, 2010). Moreover, IT personnel assist in identifying any breakdowns (i.e., Internet bandwidth or firewall settings) and work with the off-site SLP to find a viable solution.

\section{CLINICAL TRAINING}

Initial and ongoing training of personnel ensures that providers are kept abreast of advancements and best practices in telepractice methodologies. Training should include many of the following items previously discussed to ensure fidelity and successful implementation and use of telepractice. These items include: 1) an overview of the feasibility, standards, benefits and limitations of telepractice; 2) the necessity to obtain outcome data using standardized procedures and processes; 3) evidence of professional certification and licensure; 4) regularly scheduled meetings; 5) intervention planning; 6) data collection and documentation; 7) data security and privacy; 8) clinical techniques and behavioral management strategies; 9) a review of assessment and screening protocols for use with telepractice; 10) consultation with parents/guardians, general and special educators and other personnel (i.e., specialists, physicians, clinicians, etc.); 11) resources and materials to be used for telepractice; and 12) the critical collaboration with on-site personnel. 


\section{TABLE 1. TeLEPRACTICE IMPLEMENTATION PLAN}

\begin{tabular}{|c|c|c|}
\hline Needs Assessment & \multicolumn{2}{|c|}{$\begin{array}{l}\text { Assess client/facility needs and goals } \\
\text { Identify implementation team and resources } \\
\text { Assess infrastructure and support } \\
\text { Develop policies/procedures } \\
\text { Initial training on technology and approaches }\end{array}$} \\
\hline Hardware & $\begin{array}{l}\text { Clinician Side } \\
\text { Computer with } 3.0 \mathrm{GHZ} \text { or higher } \\
\text { Monitor (20" or larger) } \\
\text { Webcam (external if possible) } \\
\text { Speakers } \\
\text { Microphone }\end{array}$ & $\begin{array}{l}\text { Client Side } \\
\text { Computer with } 3.0 \mathrm{GHZ} \text { or higher } \\
\text { Monitor (20" or larger) } \\
\text { Webcam (external if possible) } \\
\text { Speakers } \\
\text { Microphone }\end{array}$ \\
\hline Software & $\begin{array}{l}\text { Videoconferencing account } \\
\text { Web conferencing account }\end{array}$ & $\begin{array}{l}\text { Videoconferencing account } \\
\text { Web conferencing link or plugin }\end{array}$ \\
\hline Internet & $\begin{array}{l}\text { High Speed Connection } \\
\text { - Incoming signal of at least } 150 \mathrm{kps} \\
\text { - Outgoing signal of at least } 150 \mathrm{kps} \\
\text { - Delay of } 200 \mathrm{~ms} \text { (less is better) }\end{array}$ & $\begin{array}{l}\text { High Speed Connection } \\
\text { - Incoming signal of at least } 150 \mathrm{kps} \\
\text { - Outgoing signal of at least } 150 \mathrm{kps} \\
\text { - Delay of } 200 \mathrm{~ms} \text { (less is better) }\end{array}$ \\
\hline $\begin{array}{r}\text { Best Practice } \\
\text { Approaches and } \\
\text { Requirements } \\
\text { for Clinic Confidentiality }\end{array}$ & $\begin{array}{l}\text { ASHA Code of Ethics } \\
\text { ASHA Scope of Practice } \\
\text { Appropriate licensure } \\
\text { Documentation of student progress } \\
\text { Monitoring of quality assurance } \\
\text { IT collaboration } \\
\text { Collaborative teaming with onsite } \\
\text { personnel } \\
\text { Supplementary equipment and } \\
\text { resources } \\
\text { Visual display strategies } \\
\text { Consultation with on-site staff } \\
\text { Carryover programs } \\
\text { Behavior management plans } \\
\text { Clinical training }\end{array}$ & $\begin{array}{l}\text { HIPAA } \\
\text { - Secure firewall } \\
\text { - Data encryption } \\
\text { - Up-to-date antivirus software } \\
\text { - Personnel trained in security } \\
\text { protocols } \\
\text { - Password management } \\
\text { - Monitor placement } \\
\text { FERPA } \\
\text { - Consent form } \\
\text { - Description of differences } \\
\text { in service deliveries }\end{array}$ \\
\hline
\end{tabular}

\section{DIRECT TELEPRACTICE SERVICES}

\section{OBJECTIVE OF CASE STUDY 1}

The objective of this single subject clinical case study was to demonstrate the effects of telepractice as a service delivery method for providing direct SLP intervention services to an individual with autism.

\section{METHODOLOGY}

This single subject case study utilized a changing condition (ABC), repeated measures research design (Ottenbacher, 1986), whereby the participant's progress on use of transition words in narratives was systematically measured while receiving direct services through a 
telepractice condition followed by an on-site condition. The participant received six telepractice and five on-site intervention sessions that targeted the IEP objective. Six pairs of probes were administered during the telepractice condition and five were administered during on-site condition.

The specific treatment objectives included retelling an event or narrative using a variety of transition words to sequence the actions and/or steps. The Individualized Education Plan (IEP) objectives, intervention and task frequency, treating graduate clinician, and the location of services remained constant throughout the study.

Baseline data were collected by the treating graduate clinician (who was not blind to the purpose of the study) over the course of two weeks prior to the implementation of the first intervention. Within this time frame, no technology, equipment or approaches were introduced for use via telepractice. Five data points were recorded prior to the initiation of the first condition and a stability of target behavior was achieved. During the intervention phases, repeated measurements were performed throughout the on-site and telepractice conditions to establish a clear pattern of the participant's performance on the target objectives.

Two treatment probes were incorporated into the beginning and end of each session. The beginning (Probe 1) and end probe (Probe 2) targeted the same IEP objective; however, different stimuli were utilized to assess the participant's skill level. The two probes were matched in terms of task difficulty and the probe stimuli were different during each intervention session and varied from the therapy stimuli.

\section{PARTICIPANTS AND SETTING}

The student participant was an 11-year-old, non-Latino white male diagnosed with autism at age ten. At the time of this study, this participant received services in the areas of speech and language, social skills, English language arts, occupational therapy and mathematics.

This study included the participation of one firstyear graduate clinician enrolled in the University of Massachusetts - Amherst's Master's program in Speech Language Pathology. The treating graduate clinician was informed of the purpose of the study and initially received two hours of clinical training on the technology, methods, software, and the documentation used to provide services. Thereafter, the graduate clinician received further training each week with a focus on methods and procedures for the implementation of evidencebased intervention for both on-site and off-site services, materials for treatment, and other responsibilities associated with the study. The treating graduate clinician was supervised at all times by a certified and licensed SLP for both treatment conditions.

The student participant attended a rural school in Western Massachusetts. Administrators at the participating school confirmed their interest and support for this study and the participant's caregiver signed a detailed informed consent document confirming voluntary participation.

\section{MATERIALS AND EQUIPMENT}

Web-based materials and stimuli were used during each intervention session for both the on-site and offsite telepractice conditions. Teaching activities were conducted and developed using SMART Notebook ${ }^{\mathrm{TM}}$ software, the PresenceLearning platform, and Big Universe, all of which offer Internet-based intervention materials. During the telepractice condition, screensharing was conducted through Adobe ${ }^{\circledR}$, ConnectNow ${ }^{\mathrm{TM}}$, or PresenceLearning.

Skype $^{\mathrm{TM}}$, a videoconferencing application with 256 bit Advanced Encryption Standard (AES) encryption, was used for the video and audio communication component (Skype Technologies SA., 2011). Adobe ${ }^{\circledR}$ ConnectNow ${ }^{\mathrm{TM}}$, a web-based conferencing system, and PresenceLearning, a web-based platform, were used for screen-sharing. While PresenceLearning is a feefor-service system, the company donated a copy for the purpose of this research. iSchoolWare, (WorldTide, Inc., 2012) a secure web-based program with 256-bit encryption, was used for all data collection, management and personnel collaboration.

The equipment used for the telepractice and traditional on-site conditions included an e-Machine computer with a 22" monitor, external speakers for sound and an external Microsoft HD webcam with an embedded microphone. The e-Machine computer ran with a Microsoft Windows 7 operating system and had a $3.1 \mathrm{GHz}$ processor and $3 \mathrm{~GB}$ memory. The Microsoft webcam had an auto-focus lens and captured $720 \mathrm{p} \mathrm{HD}$ video with $30 \mathrm{fps}$.

\section{DATA ANALYSIS}

Data on the use of transition words during narratives were collected at baseline, and throughout the onsite and telepractice treatment phases. The baseline data were compared to treatment data from the first telepractice condition using the Improved Rate Difference (IRD). To compare the telepractice vs. the on-site treatment conditions, the Tau-U method was conducted. Data entered for Tau-U was obtained through the combined score for Probe 1 and Probe 2 for each intervention session. The Tau- $U$ analysis determined if the participant's documented progress resulted in a statistically significant trend between the two treatment phases (Parker et al., 2011). For all statistical analyses, the level for non-directional, statistical significance was set at 05 . 


\section{FINDINGS}

This participant's documented outcomes yielded a statistically significant correlation between progress made during telepractice services versus progress made during on-site services for the narrative skills targeted. A comparison of the mean of the combined probe data suggests that the participant responded more favorably to telepractice services.

As seen in Table 2, the data suggest that the participant's appropriate use of transition words at baseline was a mean of $24 \%(S D=21.9)$. During the intervention phase the participant's skill level for the same target objectives increased. The participant demonstrated a mean of $91 \%(S D=10.1)$ during the first condition, which was delivered via telepractice. The IRD for baseline compared to the successive on-site phase was $100 \%$, which suggests that $100 \%$ of the data collected in the onsite intervention phase exceeded data collected in the baseline phase.

When the treatment conditions were alternated and services were conducted on-site, the participant demonstrated a reduction in the observed skill level on the use of transition words. A mean of $68 \%(S D=26.6)$ was observed during the on-site condition for the same skills that were targeted during the telepractice setting. It was anecdotally noted that the participant appeared attentive and actively participated in telepractice intervention sessions with little to no redirection. However, when the intervention conditions changed to on-site services, the participant exhibited difficulty adjusting to the change and the number of behavioral issues increased. This finding is consistent with other studies that examine the use of technology (i.e., video modeling and computer aided instruction) to provide interventions. The use of technology may provide a more predictable social environment (Wainer \& Ingersoll, 2011) therefore reducing the amount of anxiety and adverse behaviors demonstrated by students with an ASD.

For this participant, the correlated relationship between the two treatment conditions were statistically significant, $z=-2.05, p<0.05$.
TABLE 2. PARTICIPANT BASELINE, ON-SITE

AND TELEPRACTICE PROBE DATA (REPORTED

IN COMBINED RAW DATA AND PERCENTAGES)

\begin{tabular}{|l|l|l|l|}
\hline Session & Baseline & Telepractice & On-Site \\
\hline $\mathbf{1 .}$ & $0 / 5(0 \%)$ & & \\
$\mathbf{2 .}$ & $0 / 5(0 \%)$ & & \\
$\mathbf{3 .}$ & $2 / 6(33 \%)$ & & \\
$\mathbf{4 .}$ & $2 / 5(40 \%)$ & & \\
$\mathbf{5 .}$ & $5 / 11(45 \%)$ & $6 / 7(85 \%)$ & \\
$\mathbf{6 .}$ & & $15 / 16(94 \%)$ & \\
$\mathbf{7 .}$ & & $15 / 18(83 \%)$ & \\
$\mathbf{8 .}$ & & $14 / 15(96 \%)$ & \\
$\mathbf{9 .}$ & & $12 / 13(92 \%)$ & $13 / 15(87 \%)$ \\
$\mathbf{1 0 .}$ & & & $11 / 14(86 \%)$ \\
$\mathbf{1 1 .}$ & & & $7 / 11(64 \%)$ \\
$\mathbf{1 2 .}$ & & & $7 / 12(58 \%)$ \\
$\mathbf{1 3 .}$ & & & \\
$\mathbf{1 4 .}$ & & & $68 \%($ S.D. $=26.6)$ \\
$\mathbf{1 5 .}$ & & & \\
\hline Mean & & & \\
and S.D. & 24\% (S.D. = 21.9) & $91 \%($ S.D. $=10.1)$ & \\
\hline
\end{tabular}

Data is derived from the combined raw score of Probe 1 and Probe 2 for each intervention session.

A visual analysis of the data represented in Figure 1 indicated a positive mean shift when comparing baseline data to telepractice data. The level of performance resulted in negative shift once the services alternated to an on-site setting. A reduction in variability was noted when comparing baseline to telepractice data. An increase in variability was noted when comparing the telepractice to on-site data (see Table 3). 
TABLE 3. VISUAL ANALYSIS OF BASELINE, ON-SITE AND TELEPRACTICE DATA

\begin{tabular}{lllll}
\hline & Baseline & Telepractice & On-Site & Change \\
\hline Mean Shift & - & 2.8 & -.33 & - \\
Variability & 21.9 & 10.1 & - & -11.8 \\
& & 10.1 & 26.6 & 16.5 \\
\hline
\end{tabular}

Participant received services in an $A B C$ design (baseline, telepractice, on-site)

FIGURE 1: STUDENT PARTICIPANT'S DOCUMENTED PROGRESS ACROSS THE STUdY

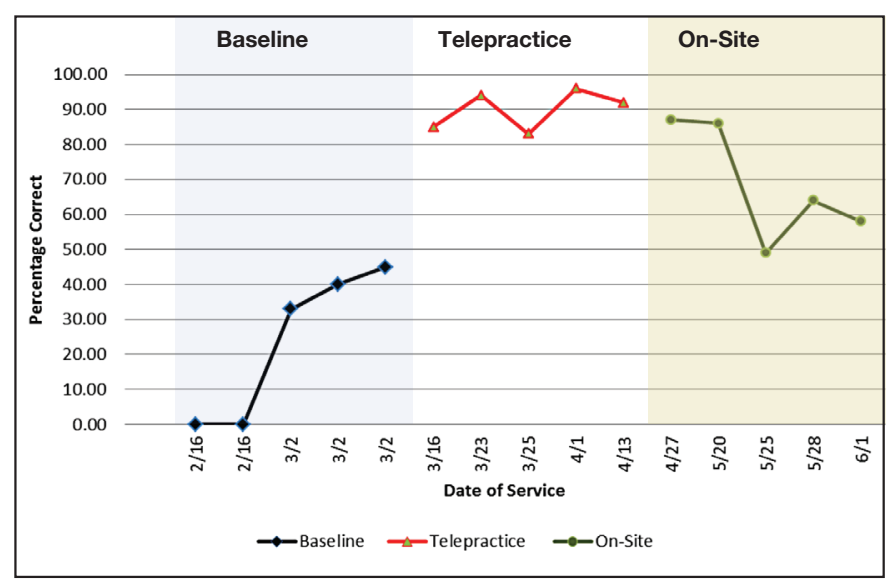

The inter-observer agreement conducted on a random $20 \%$ of the participant's probe responses, was $93 \%$. To determine the inter-observer agreement a calculation of the percentile correct for each task was conducted by converting the raw data per goal into percentage data and compared to an independent doctoral level SLP observer's rating.

\section{ACTIVE CONSULTATION \\ THROUGH TELEPRACTICE}

\author{
Objective of CASE STUDY 2
}

The objective of this second single subject study was to supervise a pre-professional graduate clinician through Active Consultation to support implementation of a participant's speech generating device (SGD) within the context of speech and language intervention. An additional objective was to evaluate the impact of Active Consultation on the client and clinician's use of an evidence-based intervention strategy known as aided language stimulation/modeling.

\section{METHODOLOGY}

A single-subject, $A B$ design was used to empirically demonstrate the outcomes that Active Consultation had on a preprofessional graduate clinician use of aided language stimulation/modeling in the context of intervention involving the client's speech generating device (SGD). To date, there is no prior literature available describing the use of such training for such purposes. As such, this initial single subject study followed a quasiexperimental design to examine the feasibility and impact of this real-time guidance.

Baseline data were collected over two, onehour sessions over the course of two weeks prior to implementing Active Consultation intervention. The researcher observed the speech and language intervention sessions and generated language samples for the client and the preprofessional clinician's use of the device. During the baseline phase, the treating clinician did not wear a Bluetooth ${ }^{\mathrm{TM}}$ earpiece, nor receive Active Consultation.

Following the two-week observation period, the Active Consultation intervention stage was implemented. This training period was defined as systematic coaching of the treating pre-professional clinician on how to implement the use of the participant's device within the intervention session. The treating pre-professional clinician was given instructions with respect to specific symbols to select/point to on the client's device, consistent with the underlying theories of aided language stimulation (Goosens, 1989) and AAC modeling (Binger \& Light, 2006). During the intervention stage, the supervising clinician observed the session via surveillance cameras and provided real-time guidance regarding the use of the device to the pre-professional clinician via the Bluetooth $^{\text {TM }}$ earpiece. While supervisory guidance was provided via a cellular network directly to the treating clinician, the directions were inaudible to the client. The preprofessional clinician was given instructions with respect to: 1) where to locate a target word/symbol; 2) 
what target phrase to model; or 3) how to prompt the participant to use his device.

\section{PARTICIPANTS AND SETTING}

One supervising clinician, one graduate student clinician and one student client participated in this investigation. The pre-professional clinician was a first-year graduate student who self-reported no prior experience working with or using a SGD. The graduate clinician was provided information regarding the objectives of this investigation and informed consent was obtained. The student participant was an 11-year-old nonLatino white male diagnosed with autism and exhibited significant expressive language deficits warranting the use of augmentative and alternative communication (an iPad with a voice output application which converted it into an SGD). The supervising clinician was a licensed speechlanguage pathologist specializing in the use of SGDs.

The student participant and graduate clinician engaged in biweekly, one hour-long intervention sessions in treatment rooms located at the University of Massachusetts Center for Language, Speech and Hearing. The treatment room format remained constant throughout the duration of the 10-week study.

\section{MATERIALS AND EQUIPMENT}

The treatment rooms were equipped with cameras that were linked to a Marshall 8.4" high resolution LCD monitor. The supervising clinician viewed the sessions in real-time on the monitor in a separate location. The pre-professional graduate clinician was fitted with a Bluetooth ${ }^{\mathrm{TM}}$ headset that was wirelessly connected to a cellular phone. The supervising clinician offered instruction and guidance to the pre-professional clinician via a cellular phone to support implementation of the student participant's SGD to deliver and address his intervention goals and objectives. All sessions were recorded using a separate, stand-alone Sony Cybershot standard definition digital camcorder with a built-in microphone.

\section{DATA ANALYSIS}

Throughout the sessions, the following variables were measured during the baseline conditions and compared to the intervention sessions: 1) the number of phrases produced by the treating pre-professional clinician; 2) the number of varied phrases produced by the treating preprofessional clinician; 3) the number of phrases produced by the student participant; and 4) the number of varied phrases produced by the student participant. For the purposes of this investigation a "phrase" was defined as one or more sequential symbol selections (not including navigating between pages on the device), where each symbol represented only one word. A frequency count was conducted to compare the variables (i.e. number of phrases generated) across the two conditions, and the mean and standard deviation were calculated. In addition, time series analysis was used to determine the significance of changes in the data. Time series analysis calculates a $\mathrm{C}$ statistic and $\mathrm{p}$-value. The $\mathrm{C}$ statistic identifies whether a trend is present in a given data set (Jones, n.d.) and the p-value determines the statistical significance of the data. For the purpose of this case study, alpha was set at .05.

To ensure the feasibility and social validity of the Active Consultation process as a mechanism to supervise and/or train, the pre-professional clinician completed satisfaction surveys after each session in which she received Active Consultation. The surveys were devised using a Likert scale with 6 questions with space for comments.

\section{FINDINGS}

Data gathered from baseline and intervention sessions revealed a dramatic increase in the number of phrases generated by the pre-professional graduate clinician and the participant, as well as the participant's progress toward meeting his specific intervention goals. As seen in Figures 2 and 3 and Table 4, during the baseline stage of the investigation neither the student participant nor the pre-professional graduate clinician used the SGD. Upon receiving the Active Consultation supervision and instruction, the graduate student clinician produced an average of 42.25 phrases (ranging from 19-85 phrases per session). Moreover, during the Active Consultation phase, the student participant produced an average of 73.37 phrases (ranging from 44-105 phrases per session) and mastered intervention goals that included using two-symbol utterances, requesting, and making comments using his SGD. In addition, the student participant produced a greater variety of phrases and the variety of phrases the client produced during the Active Consultation phase ranged from 12-28 different phrases.

A time series analysis of the data yielded a statistically significant trend in the data gathered regarding the clinician and the client's device use when comparing Baseline and Active Consultation Phases of the investigation (please see Table 4). Furthermore, review of the satisfaction surveys revealed the pre-professional clinician's satisfaction with supervision and guidance provided via Active Consultation (please see Table 5). 
FIGURE 2. TOTAL NUMBER OF PHRASES AND VARIED PHRASES PRODUCED BY THE CLINICIAN

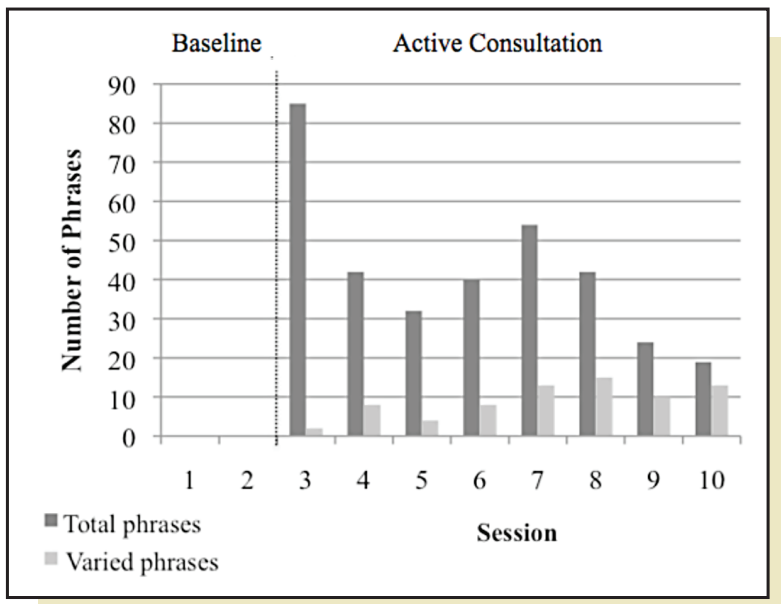

FIGURE 3. TOTAL NUMBER OF PHRASES AND VARIED PHRASES PRODUCED BY THE CLIENT

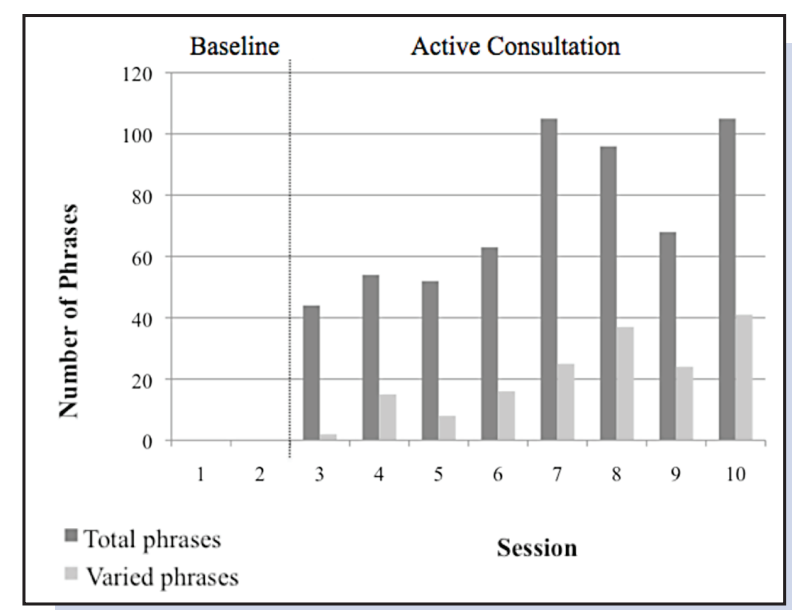



\begin{tabular}{|c|c|c|c|c|c|c|}
\hline \multirow[t]{2}{*}{ Session } & \multicolumn{2}{|c|}{ Baseline } & \multicolumn{4}{|c|}{ Active Consultation } \\
\hline & Clinician & Client & $\begin{array}{l}\text { Clinican } \\
\text { Number of } \\
\text { Phrases }\end{array}$ & $\begin{array}{l}\text { Varied } \\
\text { Phrases }\end{array}$ & $\begin{array}{l}\text { Client } \\
\text { Number of } \\
\text { Phrases }\end{array}$ & $\begin{array}{l}\text { Varied } \\
\text { Phrases }\end{array}$ \\
\hline 1. & 0 & 0 & & & & \\
\hline 2. & 0 & 0 & & & & \\
\hline 3. & & & 85 & 2 & 44 & 2 \\
\hline 4. & & & 42 & 8 & 54 & 15 \\
\hline 5. & & & 32 & 4 & 52 & 8 \\
\hline 6. & & & 40 & 8 & 63 & 16 \\
\hline 7. & & & 54 & 13 & 105 & 25 \\
\hline 8. & & & 42 & 15 & 96 & 37 \\
\hline 9. & & & 24 & 10 & 68 & 24 \\
\hline 10. & & & 19 & 13 & 105 & 41 \\
\hline Mean & 0 & 0 & 42.25 & 9.12 & 73.38 & 21.0 \\
\hline Standard Deviation & & & 20.53 & 4.55 & 24.91 & 13.48 \\
\hline C statistic & & & .541 & .547 & .513 & .620 \\
\hline$p(0.05)$ & & & .039 & .038 & .048 & .022 \\
\hline
\end{tabular}

Data is derived from the averaging the Number of Phrases and the Number of Varied Phrases produced by the clinician and the client for each session of the Baseline and Active Consultation Phases of the investigation. 


\begin{tabular}{|c|c|c|c|c|c|c|}
\hline Session & $\begin{array}{l}\text { Delivery of } \\
\text { AAC } \\
\text { Consultation } \\
\text { using } \\
\text { telepractice }\end{array}$ & $\begin{array}{l}\text { Student } \\
\text { participant's } \\
\text { progress } \\
\text { over the } \\
\text { course of the } \\
\text { study }\end{array}$ & $\begin{array}{l}\text { Your ability } \\
\text { to } \\
\text { communicate } \\
\text { with the } \\
\text { clinician over } \\
\text { the course of } \\
\text { the study }\end{array}$ & $\begin{array}{l}\text { Your attitude } \\
\text { about AAC } \\
\text { consultation } \\
\text { via } \\
\text { telepractice }\end{array}$ & $\begin{array}{l}\text { How do you } \\
\text { think } \\
\text { telepractice } \\
\text { compares to } \\
\text { face-to-face } \\
\text { consultation? }\end{array}$ & $\begin{array}{l}\text { What is the } \\
\text { likelihood } \\
\text { you would } \\
\text { recommend } \\
\text { Active } \\
\text { Consultation } \\
\text { to your } \\
\text { colleagues? }\end{array}$ \\
\hline \multicolumn{7}{|l|}{ 1. * } \\
\hline \multicolumn{7}{|l|}{ 2. * } \\
\hline 3. & 3 & 4 & 4 & 3 & 4 & 4 \\
\hline 4. & 4 & 5 & 5 & 5 & 5 & 5 \\
\hline 5. & 5 & 5 & 5 & 5 & 5 & 5 \\
\hline 6. & 5 & 5 & 5 & 5 & 5 & 5 \\
\hline 7. & 5 & 5 & 5 & 5 & 5 & 5 \\
\hline 8. & 5 & 5 & 5 & 5 & 5 & 5 \\
\hline 9. & 5 & 5 & 5 & 5 & 5 & 5 \\
\hline 10. & 5 & 5 & 5 & 5 & 5 & 5 \\
\hline Mean & 4.625 & 4.875 & 4.875 & 4.75 & 4.875 & 4.875 \\
\hline
\end{tabular}

Data is derived from satisfaction surveys that used a 5-point Likert scale with $1=$ Not Very Good, 2 = Below Average, 3 $=$ Average, 4 = Above Average, and $5=$ Very Good. Averages were calculated for each question over the course of the Active Consultation Phase.

${ }^{*}$ Satisfaction surveys were not administered during the Baseline Phase. 


\section{CONCLUSIONS}

Due to the critical shortage of SLPs, professionals should consider more innovative, technology-driven methods for service delivery. The primary goal of these studies was to describe a clinical model and provide guidelines that support services through telepractice and Active Consultation. As technology continues to improve and evolve, these protocols and service delivery models help facilitate and provide a standard for the implementation of high-quality telepractice services.

The two single subject case studies provide data that support telepractice and Active Consultation as effective methods of service delivery for direct and indirect intervention. The student participant with autism in Case Study 1 received direct telepractice services and made advancement towards his IEP goals. Similarly, in Case Study 2 the pre-professional graduate student clinician receiving Active Consultation supervision and guidance, and the student participant with autism, demonstrated beneficial outcomes in language production as expressed using a SGD. These two clinical case studies demonstrate that direct and indirect services via telepractice are feasible forms of service delivery for individuals with ASD and the professionals serving such individuals; and contribute to a growing body of literature establishing the use and benefits of a telepractice service delivery method for speech and language services.

\section{LIMITATIONS OF THE STUDY}

There are several limitations associated with the two case studies presented in this article. First and foremost, the treatment conditions were not alternated and as a result, the findings obtained from both intervention settings were not replicated within this study. Moreover, these studies were case examples involving a small number of participants and the ability to generalize the results to other students with ASD and/or other individuals with communication disabilities is limited. The treating clinicians were aware of the aims targeted in the studies and were therefore not blind to the purpose of the research.

\section{FUTURE RESEARCH}

Given these successful results in providing intervention services via telepractice to students diagnosed with ASD in these case examples, and considering the critical national shortage of school-based speech-language pathologists, it is essential that this research strand continue to be investigated. Future research should explore the use of telepractice with a greater number of students with ASD and with a greater variety of target skills in an alternating treatment design or other experimental designs that better control for threats to internal and external validity.

In the first case study, the treating clinicians reported that the level of attention demonstrated by the student participant seemed to be greater when services were rendered through telepractice. This observation is consistent with other research that has been conducted on the use of technology such as video modeling and computer aided programs to provide intervention in the development of communication skills to students with an ASD. It would be beneficial for the future of telepractice to determine if and what similarities exist between telepractice interventions and use of other innovative technologies to deliver services. An important research strand would be to determine if these innovative technological approaches could be facilitated via telepractice.

Future research should also examine if telepractice can be used for the delivery of other evidence-based interventions such as functional communication training and behavioural assessments, parent implemented interventions, peer-mediated interventions, the use of speech generating devices, pivotal response training and social narratives. A determination on the appropriateness of telepractice to deliver these interventions will strengthen the wide-spread acceptance of telepractice.

Telepractice has the potential to significantly improve access to services for individuals with special needs as well as to assist speech and language professionals in working more effectively with these individuals. The continuation of this research must further define best practice or evidence-based approaches within this framework and clinical service delivery models. There is a vital need to demonstrate evidence-based practices and methodologies for all assessment and intervention services provided to clients with communicative disabilities and in particular, services provided through telepractice. The impact of telepractice technology will undoubtedly increase the quantity, quality and accessibility of services and support provided to individuals in need of services, including graduate students, speech/language assistants, general and special educators and paraprofessionals.

\section{ACKNOWLEDGEMENT}

At the time of these investigations, Michelle Boisvert and Nerissa Hall were funded by a grant awarded to Dr. Mary Andrianopoulos by the U.S. Department of Education, Office of Special Education and Rehabilitative Services (CFDA 84.325D, H325D080042). 


\section{REFERENCES}

1. Adobe ${ }^{\circledR}$ ConnectNow ${ }^{\mathrm{TM}}$ [Software]. (n.d.). San Jose, CA: Adobe Systems Incorporated.

2. American Association for Employment in Education. (2008). Educator supply and demand in the United States. Retrieved from http://www.aaee.org/cwt/ external/wcpages/resource/

3. American Speech-Language-Hearing Association. (2005). Speech-language pathologists providing clinical services via telepractice: Position statement. Retrieved from http://www.asha.org/policy/PS2005-00116.htm

4. American Speech-Language-Hearing Association. (2010). Professional issues in telepractice for speechlanguage pathologists. Retrieved from http://www.asha. org/policy/PI2010-00315.htm

5. Binger, C., \& Light, J. (2006). Demographics of preschoolers who require AAC. Language, Speech, and Hearing Services in Schools, 37, 200-208.

6. Boisvert, M, Lang, R., Andrianopoulos, M., \& Boscardin, M. (2010). Telepractice in the assessment and treatment of individuals with autism spectrum disorders: A systematic review. Developmental Neurorehabilitation, 13, 423-432.

7. Centers for Disease Control and Prevention. (2012). Autism spectrum disorders. Retrieved from http://www. cdc.gov/ncbddd/autism/index.html

8. Denton, D., \& Gladstone, V. (2005). Ethical and legal issues related to telepractice. Seminars in Hearing, 26(1), 43-52.

9. Family Educational Rights and Privacy Act of 1974, 20 U.S.C. § $1232 \mathrm{~g}(1974)$.

10. Goosens, C. (1989). Aided communication intervention before assessment: A case study of a child with cerebral palsy. Augmentative and Alternative Communication, 5(1), 14-26.

11. Health Insurance Portability and Accountability Act of 1996 (HIPAA), 42 U.S.C. §§ 300gg et seq (P.L. 104-191 1996).

12. Individuals with Disabilities Education Improvement Act. (2004). 20 U.S. C. § 1400 et seq.

13. Jones, P. (n.d.). Single-case research and statistical analysis: A practitioner's guide. Retrieved from http:// www.pjclinic.com/singlecase/scsa_onlineguide.htm\#ch4

14. Juenger, J. (2009, September 22). Telepractice in the schools: Virtual services help clinicians do more with less. Retrieved from http://www.asha.org/publications/ leader/2009/090922/090922f/

15. Kazdin, A. (2011). Single-case research designs (2nd ed.). New York: Oxford University Press.

16. Koegel, L., Matos-Fredeen, R., Lang, R., \& Koegel, R. (2011). Interventions for children with autism spectrum disorders in inclusive school settings. Cognitive and Behavioral Practice, 18, 421-588.

17. Miller, T., Morgan, R., \& Wood, J. (2009). A telehealth technology model for information science in rural settings. International Journal of Healthcare Delivery Reform Initiatives, 1, 242-258.

18. Mirenda, P., \& lacono, T. (2009). Autism spectrum disorders and AAC. Baltimore, MD: Paul H. Brooks Publishing Co.

19. National Autism Center. (2011). A parent's guide to evidence-based practice and autism. Retrieved from http://www.nationalautismcenter.org/pdf/nac_parent_ manual.pdf
20. National Professional Development Center on Autism Spectrum Disorders. (n.d.). Evidence-based practice briefs. Retrieved from Professional Development Center on Autism Spectrum Disorders: http://autismpdc.fpg. unc.edu/content/briefs

21. National Research Council. (2001). Educating children with autism. Washington, DC: National Academy Press.

22. No Child Left Behind Act of 2001. (2001). 20 U.S.C. § 6319. Retrieved from http://www2.ed.gov/policy/elsec/ leg/esea02/107-110.pdf

23. Olive, M., Cruz, B., Davis, T., Chan, J., Lang, R., O’Reilly, M., \& Dickson, S. (2007). The effects of enhanced milieu teaching and a voice output. Journal of Autism and Developmental Disorders, 37, 1505-1513.

24. Ottenbacher, K. (1986). Reliability and accuracy of visually analyzing graphed data from single-subject designs. American Journal of Occupational Therapy, 40, 464-469.

25. Parker, R., Vannest, K., Davis, L., \& Sauber, S. (2011). Combing nonoverlap and trend for single-case research: Tau-U. Behavior Therapy, 42, 284-299.

26. Paul, R. (1987). Handbook of autism and pervasive developmental disorders. In D. \&. Cohen, Handbook of autism and pervasive developmental disorders (pp. 301315). Silver Spring: V.H. Winston.

27. PresenceLearning. (2012). Retrieved from http:// presencelearning.com

28. Schlosser, R., \& Wendt, O. (2008). Effects of augmentative and alternative communication intervention on speech production in children with autism: A systematic review. American Journal of Speech-Language Pathology, 17, 212-230.

29. Skype Technologies SA. (2011). Skype. Retrieved from www.skype.com

30. SMART Technologies. (2012). SMART Notebook. Retrieved from: http://smarttech.com/notebook

31. Toglia, T. (2007). How does FERPA affect you? Tech Directions, 67, 32-35.

32. U.S. Department of Education. (2012). Teacher Shortage Areas Nationwide Listing 1990-1991 through 2012-2013. Washington, D.C.: U.S. Department of Education.

33. Van Dusen, W. (2004). FERPA: Basic guidelines for faculty and staff a simple step-by-step approach for compliance. Retrieved from NACADA Clearinghouse of Academic Advising Resources: http://www.nacada.ksu. edu/Clearinghouse/advisingissues/FERPA-Overview.htm

34. Wainer, A., \& Ingersoll, B. (2011). The use of innovative computer technology for teaching social communication to individuals with autism spectrum disorders. Research in Autism Spectrum Disorders, 5, 96-107.

35. WorldTide, Inc. (2012). iSchoolWare Caseload Management. Retrieved from http://www.ischoolware. com 
